\title{
Magnetic Resonance Imaging Features of Prostate Mucinous Adenocarcinoma
}

\author{
Prostat Müsinöz Adenokanserinin Manyetik Rezonans Görüntüleme Bulguları
}

\author{
(D) Canan Altay ${ }^{1}$, (D) Uygar Mutlu ,(D) Ozan Bozkurt², (D) Ömer Demir², (D) Kutsal Yörükoğlu³, (D) Aras Emre Canda ${ }^{4}$, (D) Mustafa Seçil ${ }^{1}$ \\ 'Dokuz Eylül University Faculty of Medicine, Department of Radiology, Izmir, Turkiye \\ ${ }^{2}$ Dokuz Eylül University Faculty of Medicine, Department of Urology, Izmir, Turkiye \\ ${ }^{3}$ Dokuz Eylül University Faculty of Medicine, Department of Pathology, Izmir, Turkiye \\ ${ }^{4}$ Dokuz Eylül University Faculty of Medicine, Department of General Surgery, Izmir, Turkiye
}

\section{Introduction}

Prostate adenocarcinoma is the most common cancer and the second most common cause of cancer-related death among men in the Western world (1). It is more common in patients older than age 50 years. The mucinous subtype of prostate adenocarcinoma, also referred to as colloid adenocarcinoma, is extremely rare as a primary prostate lesion. The frequency of mucinous adenocarcinoma of the prostate, defined by the presence of more than 25\% extravasated mucins, is approximately $0.2 \%(2)$.

The mucinous subtype of prostate adenocarcinoma has an aggressive clinical behavior (3). Surgical resection is the main therapeutic option (2). In this article, we describe the clinical and magnetic resonance imaging (MRI) features with histopathological correlation in a patient with mucinous adenocarcinoma of the prostate.

A 48-year-old man presented with urinary symptoms described as progressive urinary retention that was not associated with pelvic pain or fever. Physical examination was unremarkable. The prostate-specific antigen level was $2.55 \mathrm{ng} / \mathrm{mL}$ (normal range, $<4.0 \mathrm{ng} / \mathrm{mL}$ ), and all the other serum tumor markers were found to be normal.

MRI of the prostate was performed using a 1.5-T scanner and a pelvic phased array coil. MRI of the prostate revealed a tumor extending from the base to the apex of the prostate.
The transitional zone of the prostate gland comprised a macrolobulated heterogeneous hyperintense mass with a hypointense capsule on T2-weighted images (WIs) (Figure 1) The prostatic mass exhibited central and peripherally hyperintense areas within the mass on T1-WIs, compatible with mucin lakes (Figure 2). After contrast administration, the lesion demonstrated strong heterogeneous enhancement (Figure 3). Diffusion-Wls revealed heterogeneous diffusion-restricted regions in the mass, compatible with solid portions of the mass (Figures $4 a, b$ ).

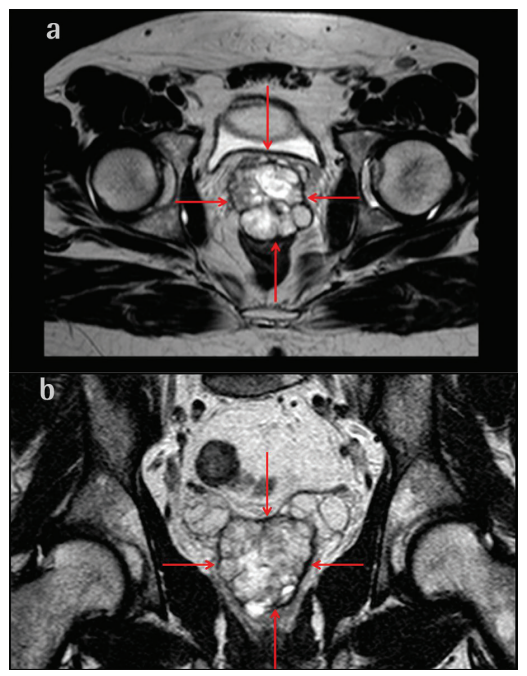

Figure 1. Axial and coronal turbo spin echo T2-weighted images reveal a well-defined, macrolobulated heterogenous hyperintense lesion with hypointense areas within prostate gland (red arrows)

Correspondence: Canan Altay MD, Dokuz Eylül University Faculty of Medicine, Department of Radiology, İzmir, Turkiye E-mail: drcananaltay@gmail.com ORCID-ID: orcid.org/0000-0003-0417-7770

Received: 28.03.2018 Accepted: 02.04.2018

Cite this article as: Altay C, Mutlu U, Demir Ö, Yörükoğlu K, Canda AE, Seçil M. Magnetic Resonance Imaging Features of Prostate Mucinous Adenocarcinoma. J Urol Surg 2018;5(2):140-142

๑Copyright 2018 by the Association of Urological Surgery / Journal of Urological Surgery published by Galenos Publishing House. 
The mass invaded the serosa of the rectum, and fat tissue was obliterated in the pre-rectal region. No enlarged lymph node or metastasis was identified.

Surgery was performed using a retropubic approach. The patient underwent radical cystoprostatectomy and resection of the invaded rectum segment. Colostomy surgery was also performed. Histopathological examination confirmed the presence of prostatic adenocarcinoma with extraluminal mucinous pools involving $>50 \%$ of the tumor volume (Figure 5 ). The final Gleason score was $4+4=8$, and the stage was pathological T4. There was no recurrence detected in follow-up imaging studies after surgery. Lung metastasis was observed on computed tomography of the thorax 36 months after the diagnosis.

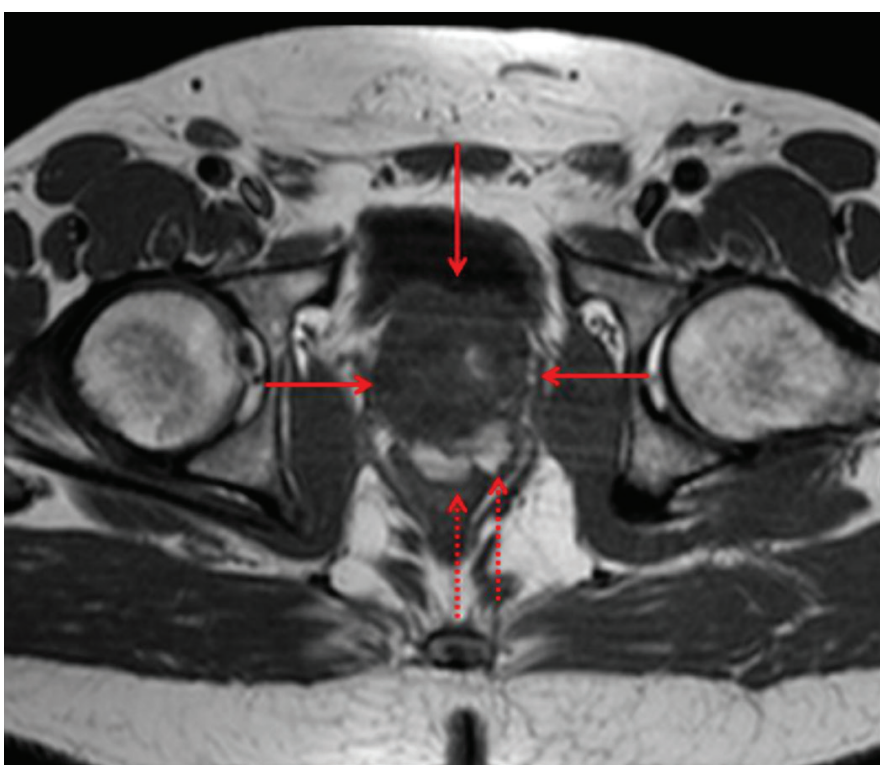

Figure 2. Axial turbo spin echo T1-weighted image reveals central and peripherally hyperintense areas (stippled arrows) within the mass (red arrows) compatible with mucin lakes

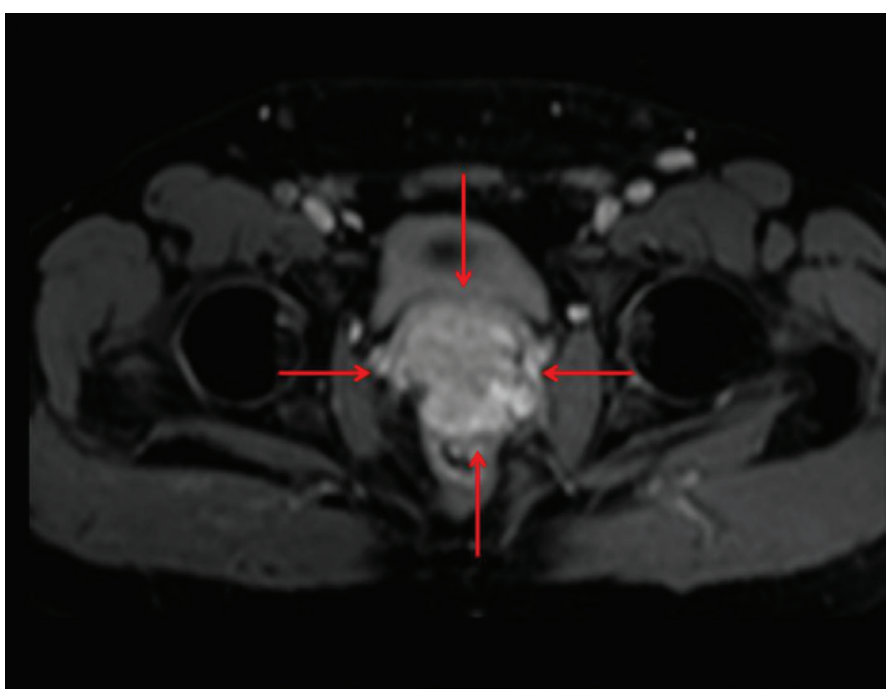

Figure 3. The prostate mass heterogenous enhanced on fat suppressed contrast-enhanced T1 weighted image (red arrows)
Mucinous adenocarcinoma of the prostate is a rare subtype of prostate cancer characterized by large pools of extracellular mucins, which by definition comprise at least $25 \%$ of the tumor

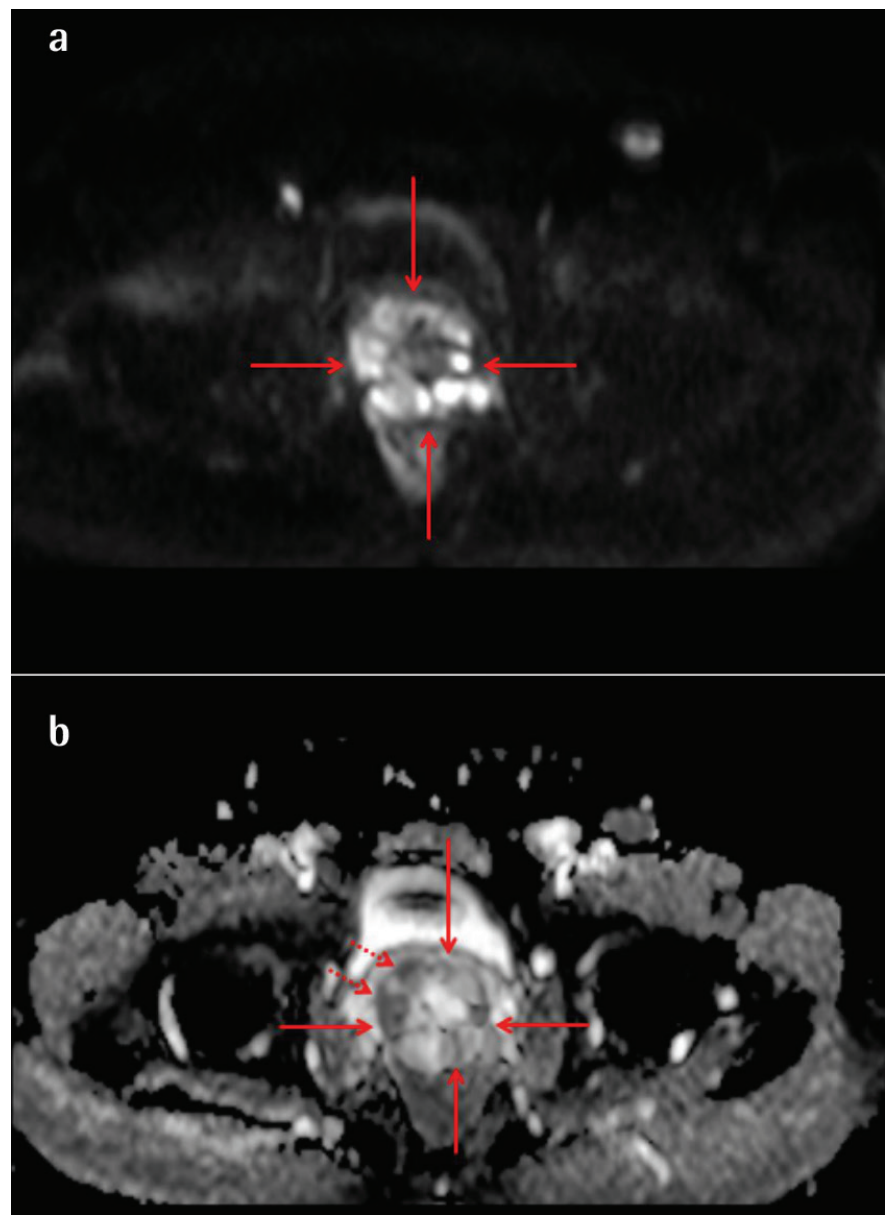

Figure 4. The prostate mass (red arrows) hyperintense on diffusion weighted image (a) and hypointense on apparent diffusion coefficient map (b) consistent with restricted diffusion (stippled arrows)

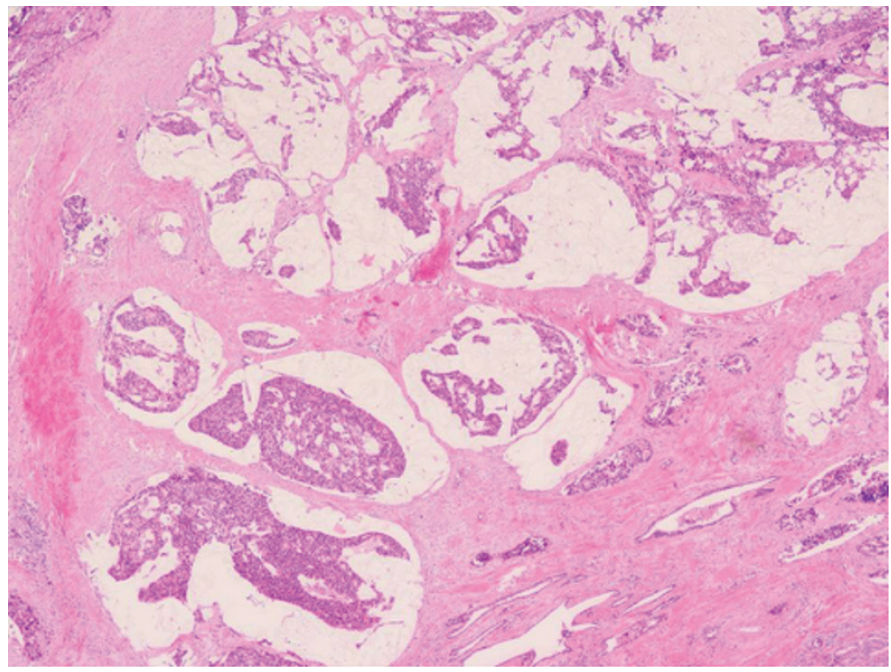

Figure 5. Mucinous carcinoma with cell nests embedded in mucinous lakes in radical prostatectomy specimen (Hematoxylin\&eosin staining; original magnification 100x) 
volume. Mucinous adenocarcinomas represent approximately $0.2-0.4 \%$ of all prostate adenocarcinomas $(1,3)$.

The etiology of mucinous adenocarcinoma of the prostate remains unclear, and it is thought that the risk factors for mucinous adenocarcinoma of the prostate are similar to those for adenocarcinoma of the prostate, which are related to genetic, environmental, androgen, and other factors. The etiology of mucinous adenocarcinoma of the prostate may be related to the endocrine epithelium of the prostate (4).

Prostate involvement by mucinous adenocarcinoma of the intestine, the bladder or urethra is histologically similar to mucinous adenocarcinoma of the prostate. The infiltrating components of these extra-prostatic mucinous cancers contain mucin pools lined by columnar mucinous epithelium and show different degrees of nuclear atypia. Even then, mucinous adenocarcinoma of the prostate includes single bland and cribriform glands. Prostatic mucinous adenocarcinoma is only uncommonly associated with true intracellular mucin-positive "signet ring cells" (2).

Moreover, $60-90 \%$ of adenocarcinomas of the prostate secrete some mucoid material. Thus, these common tumors differ from true mucinous carcinoma primarily in degree. A criterion for the diagnosis of mucinous adenocarcinoma is a primary prostatic acinar tumor with the presence of at least $>25 \%$ of an excised tumor consisting of tumor cells and clusters of cells floating in mucin lakes $(5,6,7,8)$.

Mucinous adenocarcinoma of the prostate usually has no obvious symptoms during the early stages, and most of the symptoms are similar to those of benign prostatic hyperplasia. However, when the tumor invades the urethra and bladder neck, bladder irritation, and even acute urinary retention and hematuria, may occur (4). The main treatment option for mucinous adenocarcinoma of the prostate is radical prostatectomy. However, rarely, hormone therapy and/or radical radiotherapy have been used (7).

Multiparametric MRI is the best useful diagnostic tool for the pre-operative staging of prostate cancer (8). On MRI, mucinous prostate cancer appears as high-signal-intensity lesions on T1- and T2-Wls owing to the mucin component. However, in some cases, variable T2-weighted signal intensities may be observed because of a lower mucin content or different chemical composition, both of which induce shortening of the T2 relaxation time (5). An early small series of patients with mucinous adenocarcinoma of the prostate suggested that these tumors show high T2 signal intensity rather than the usual low T2 signal intensity of non-mucinous adenocarcinoma of the prostate $(9,10)$. The differential diagnosis includes cystic prostatic hyperplasia, abscesses, and cystadenomas $(5,9)$.

\section{Conclusion}

Primary prostatic mucinous adenocarcinoma is a rare and aggressive malignant tumor. The MRI features of mucinous adenocarcinoma are non-specific, however, hyperintense regions inside prostatic tumors are observed on T1- and T2-WIs because of the presence of mucin pools. MRI is also helpful for detecting invasion of adjacent tissues and for disease staging.

Keywords: MRI, Prostate carcinoma, Mucinous adenocarcinoma

Anahtar Kelimeler: MRG, Prostat kanseri, Müsinöz adenokanser

\section{Ethics}

Peer-review: Internally peer-reviewed.

\section{Authorship Contributions}

Surgical and Medical Practices: O.B., Ö.D., A.E.C., K.Y., Concept: C.A., Ö.D., Design: C.A., O.B., Data Collection or Processing: U.M., Analysis or Interpretation: M.S., Literature Search: C.A., U.M., Writing: C.A., U.M.

Conflict of Interest: No conflict of interest was declared by the authors.

Financial Disclosure: The authors declared that this study received no financial support.

\section{References}

1. Verma S, Rajesh A. A clinically relevant approach to imaging prostate cancer: review. AJR Am J Roentgenol 2011;196(3 Suppl):S1-10.

2. Osunkoya AO, Nielsen ME, Epstein Jl. Prognosis of mucinous adenocarcinoma of the prostate treated by radical prostatectomy: a study of 47 cases. Am J Surg Pathol 2008;32:468-472.

3. Westphalen AC, Coakley FV, Kurhanewicz J, Reed G, Wang ZJ, Simko JP. Mucinous adenocarcinoma of the prostate: MRI and MR spectroscopy features. AJR Am J Roentgenol 2009;193:238-243.

4. Guang-Zhen WU, Wang Qi-Fei, Quan-Lin LI, Zhang Zhi-W, Tang OZ. Mucinous Adenocarcinoma of Prostate: A Case Report and Review of Literature. J Clin Case Rep 2017;7:4.

5. Chang JM, Lee HJ, Lee SE, Byun SS, Choe GY, Kim SH, Seong CK, Kim SH. Pictorial review: Unusual tumours involving the prostate: radiologicalpathological findings. Br J Radiol 2008;81:907-915.

6. Osunkoya A0. Mucinous and secondary tumors of the prostate. Mod Pathol 2018;31:80-95.

7. Wu $T, C a D$, Wang $H, Y u X$. Primary mucinous adenocarcinoma of the prostate: a case report and literature review. Int J Clin Exp Med 2016;9:87928794.

8. Soylu FN, Eggener S, Oto A. Local staging of prostate cancer with MRI Diagn Interv Radiol 2012;18:365-373.

9. Outwater E, Schiebler ML, Tomaszewski JE, Schnall MD, Kressel HY. Mucinous carcinomas involving the prostate: atypical findings at MR imaging. J Magn Reson Imaging 1992;2:597-600.

10. Hussain SM, Outwater EK, Siegelman ES. MR imaging features of pelvic mucinous carcinomas. Eur Radiol 2000;10;885-891. 